\title{
Research on Power System Planning and Reconfiguration under Energy Saving and Emission Reduction
}

\author{
Yuqiong Zhang ${ }^{a}$, Yuzhe Zhang ${ }^{b}$, Chenchen Wang ${ }^{c}$, Zhao Yang ${ }^{d}$, Yang Tang ${ }^{e}$ \\ State Grid Henan Electric Power Company Luoyang Power Supply Company, \\ Luoyang 471000, China \\ a997463132@qq.com, b1015903240@qq.com
}

Keywords: Energy conservation, power systems, planning reconstruction

\begin{abstract}
Energy conservation has become China's sustainable development, the only way to ensure the long-term interests of the Chinese nation, but also to deal with the urgent need for global energy crisis and climate change. As a crucial part of the power system energy consumption and secondary energy supply is the top priority of the entire energy conservation. With the deepening of energy conservation policies continue to strengthen, the power system is ushering in a series of new changes and new problems, the urgent need for new research and analysis methods. In this context, this paper takes the power system energy conservation as the fundamental starting point, focusing on the power system planning; some key issues are closely related to operation.
\end{abstract}

\section{Introduction}

With coal, oil, natural gas and other fossil fuels depleting, and contribute to global warming, acid rain, air pollution and other environmental problems, energy use in energy conservation has received increasing attention around the world. Although China is a country with extensive resources, but the per capita amount of fossil fuels is far below the world average per capita oil reserves are only one tenth of the world average, abundant reserves of coal resources per capita is only the world average about half. Although in recent years China has been sparing no effort to improve energy efficiency, but due to technical constraints as well as some of the industrial structure, China's energy efficiency is still relatively low. In 2010, China's primary energy consumption reached 3.25 billion tons of standard coal, as the world's primary energy consumption country, but energy intensity per unit of output but is three times the United States five times that of Japan, energy efficiency needs to be further improved. Meanwhile, with the massive growth of fossil energy consumption and pollutant emissions caused by increased year by year, not only caused a series of social and economic development and hinder affecting people's lives healthier environment pollution problems, but also so that our country is facing huge The international public opinion and political pressure. Therefore, vigorously promote energy conservation has become our country to achieve sustainable economic and Society.

The power industry is a major industry of energy consumption and pollutant emissions. Statistics show that China's power industry, electricity consumption reached about half of the total coal consumption, carbon dioxide, sulfur dioxide and nitrogen oxide emissions caused by the generation of goods respectively reached $40 \%$ of total emissions, $50 \%$ and $20 \%$ or more, which makes the power industry to become China's most important energy saving strategies. Meanwhile, as China's production and social life electrification of industrial deepening, as a secondary energy electricity being gradually raise the proportion of overall energy consumption, and therefore energy saving electric power industry will also help reduce China's industrial production and Hidden Costs of social life, improve international competitiveness and living standards.

\section{Analysis of China's Electric Power Supply System Lifecycle Carbon Emissions Flow}

Our country is a vast, resource-rich country, but China's economic development and distribution of energy resources preached apparent reverse distribution. China's economy is more developed, the 
huge energy consumption is mainly concentrated in the southeast coastal areas, but the coal, oil and other energy resources are mainly concentrated in the northwest and north China, water resources are mainly concentrated in the southwest region. Economic development and distribution of energy resources makes the reverse of inter-regional economic development to support energy delivery becomes the only option. As China's economy is growing, the size of the inter-regional energy transmission has been expanded, which also implies the transfer of large amounts of carbon emissions. In order to achieve the national emission reduction targets, requires a unified distribution across the country, between the various regions in the overall planning, therefore, it is necessary to study energy transport in carbon emissions implied by the transfer.

Carbon emissions flow analysis theory and combining the full life cycle assessment method to build a full life-cycle emissions flow analysis model for power supply systems, analyzes of carbon emissions and carbon emission transfer characteristics of China's power supply system, power system and carbon emissions development policy formulation and planning sub-regional electric power industry made some suggestions.

Power structure in different regions, namely water, fire, nuclear, wind power generation and other types of construction, significantly influenced the local transportation and carbon emissions intensity outward transfer of power, and this power structure is very dependent on the local energy resources. For the East, the amount of emissions of carbon input from the same amount of electricity caused by the North is much higher than the central China, the reason is that North China is rich in coal resources, but a lack of water resources, power generation is a major North China forms of electricity generation, while the central region has abundant water resources, its hydropower generation accounts for nearly half of the national total.

With the rapid growth of electricity demand, the development of hydropower alone cannot meet the expanding demand for power, including the rapid growth of various forms of generation of thermal power, nuclear power and wind energy, solar energy and other renewable energy sources, including electricity generation will be the inevitable trend. Geographical distribution, renewable energy rich areas far from the centers mostly, for example, water resources are mainly concentrated in the southwest, wind and solar energy resources are mainly concentrated in the north, northwest and northeast regions, only a portion of the available wind resource distribution Shandong, Jiangsu and other coastal areas, which gives the effective use of renewable energy resources caused difficulties. Since renewable energy cannot be the same as the coal is directly transferred inevitably require local use of renewable energy power generation and inter-regional transportation. Nuclear power plants generally have the flexibility to build in the area close to the load center, but for security reasons, the capacity growth in the densely populated center of the load will be greatly limited. In terms of thermal power in the future for a long period of time, China's thermal power installed capacity will continue to increase, and gradually promote the use of more efficient and cleaner power generation technologies such as supercritical and ultra-supercritical units, carbon capture and storage power systems .

Despite years of construction, our country has a strong coal transport network, but because of transport capacity constraints and the constraints of geography and climate conditions, the eastern and coastal areas still face a shortage of electricity problem frequently, especially in the summer and the larger winter electricity load, thermal power stations often face the dilemma of emergency coal storage. As another means of long-distance transmission, energy and inter-regional power transmission in recent years more and more attention. Especially with the increasing power load southeast coastal areas and faced enormous pressure of environmental pollution, more and more thermal power station is planned in the western region of our country, to the nearest coal into electrical energy, and through distance transfer of large capacity transmission mode to load centers in southeastern region. With AC and DC ultra, ultra high voltage transmission technology matures; China's long-distance high-capacity transmission channel will gradually improve. 


\section{Power Investment Risk Assessment and Uncertain Decision-making under Energy Saving and Emission Reduction}

In the global energy crisis and environmental degradation in the background, countries in the world have introduced energy conservation policy to restrict energy consumption and pollution emissions suppression. In contrast, energy conservation situation faced by our country even more severe, while China's current low energy efficiency, pollution is serious, the other hand, China is still in the industrialization and modernization process which social development is inseparable a lot of energy supply support. Meanwhile, energy conservation issues facing our country are more complex, economic development and a serious imbalance in the distribution of energy will continue to be a great challenge China's energy supply. Vigorously implement the energy saving is the inevitable choice of China's energy development strategy, but facing a serious situation and complex issues, China's energy conservation policy need to continue to explore and improve practice in the dark, with strong uncertainty.

In the presence of uncertainty, risk assessment and decision-making in electricity investment is a key issue relating to investment success and electrical power system can safe, economical operation. Under conditions of uncertainty at home and abroad to invest in risk assessment and decision-making power has been a lot of research results, made a number of models and methods of analysis and decision-making. However, there is often a strong correlation between the price of fuel and electricity prices, such as environmental emissions and electricity costs, etc., it is necessary to take full account of its risk assessment between some uncertain factors affect power investment, the existing research in this still lacking. Therefore, this chapter will assess the reliability of commonly used in reference to a power conversion method investment risk assessment to build a correlation between a risk assessments taking into account uncertainties. Furthermore, this chapter presents a sensitivity analysis of investment decisions in probabilistic risk assessment on the basis of a method to compensate for the current lack of sensitivity analysis in the presence of risk quantification.

Power invested by the scale of people, and long payback period and other factors have a strong risk, pressure and energy conservation policy is uncertain energy environment, further increasing the risk of electric power investments. On the basis of risk assessment indicators and targets will be uncertain probability characteristic weight added to the sensitivity analysis of power investment programs decision to construct the probabilistic sensitivity analysis indicators power investment program making its calculation, and actual cases of mentioned models and methods of authentication, data results show that the proposed model and method will help decision-makers to identify key indicators to make more rational and stable decisions and help policy makers develop risk mitigation strategies.

\section{Summary}

China's economic development has experienced more than 30 years of rapid growth, a substantial increase in comprehensive national strength and people's living standards, but also consumes a lot of energy and resources, cause serious environmental pollution and emissions. Energy shortage and environmental pollution tremendous pressure limit is becoming China's economic and social sustainable development of the core problem, and vigorously promote energy conservation is the inevitable choice without delay. Power industry is the whole strategy of the most important energy saving, energy saving in the environment is ushering in a new series of changes and problems, the urgent need for new research and analysis methods. 


\section{Reference}

[1]Qing H U, Huang G, Wei L I, et al. Energy-saving and Emission Reduction Planning on Power Generation Side Based on Fuzzy Feasibility Analysis[J]. Modern Electric Power, 2013.

[2]Jian nan Q I. Study on Planning and Building of Energy Saving and Emission Reduction System in Coal Enterprise[J]. Coal Economic Research, 2012.

[3]Li J L, Xiong X, Yang S L. Wind/Storage System Capacity Configuration Research Based on the Benefits of Energy Saving and Emission Reduction[J]. Advances in Energy Science \& Technology, 2013, 291-294.

[4]Rao P, Peng C H. A Research on Power Dispatch of Energy-saving and Emission-reduction Generation Based on the Improved Differential Evolution Algorithm[J]. Journal of East China Jiaotong University, 2010.

[5]Yan G, Liu H, Gang M U, et al. Crowding-out Effect of Wind Power Under Special Condition and Comprehensive Evaluation on Energy-Saving and Emission Reduction Benefits of Wind Power Generation[J]. Power System Technology, 2012, 36(4):51-56.

[6]Liu Y, Hou H, Zhou K, et al. Research on Construction of Management and Control System of Electricity Bill Risks in Power Grid Enterprises under Energy Conservation and Emission Reduction Principle[J]. International Journal of Business \& Management, 2011, 6(8).

[7]Zhou Z. Present Situation Analysis on Combustion Fuel under the Background of "Energy Saving and Emission Reduction"[J]. Internal Combustion Engine \& Powerplant, 2012. 